\title{
ASPECTOS DA CISÃO ERGATIVA NA LÍNGUA YAWANAWÁ (PANO)
}

\section{Aldir Santos de Paula ${ }^{\star}$}

Resumo: Este trabalho tratará do sistema de marcação de caso da língua Yawanawá, em especial das cisões existentes no mesmo. A língua possui uma morfologia aglutinante com uso de sufixos e se caracteriza como de verbo final. Os verbos são classificados em transitivos e em intransitivos, e estes são sub-classificados em ativos e estativos. Os verbos intransitivos ativos estão associados a ações que não afetam um paciente e os intransitivos estativos descrevem estados permanentes.

Palavras-chave: Línguas indígenas. Línguas Pano. Língua Yawanawá. Marcação de caso.

\section{Introdução}

A língua Yawanawá pertence à família lingüística Pano e é falada por cerca de 400 pessoas, que moram na parte sul da Terra Indígena do Rio Gregório, estado do Acre. Tipologicamente, a língua Yawanawá é aglutinante, de base sufixal, possui uma ordem sintagmática do tipo AOV/SV e um sistema de marcação de caso do tipo ergativo-absolutivo.

Este artigo tem como objetivo apresentar uma discussão sobre o sistema de marcação de caso da língua Yawanawá, em especial as cisões existentes no mesmo, dentro de uma perspectiva funcionaltipológica (COMRIE, 1978; GIVÓN, 1984 E DIXON, 1994). Nos estudos tipológicos, o estudo de marcação de caso de uma língua se apresenta como um dos parâmetros mais importantes.

- Professor e pesquisador do Programa de Pós-graduação em Letras e Lingüística da Faculdade de Letras da Universidade Federal de Alagoas (FALE/UFAL). Doutor em Lingiística pela Unicamp. 


\section{Sistema de marcação de caso}

A marcação de caso pode ser entendida como os vários mecanismos utilizados por uma língua para codificar as funçōes gramaticais sintático-semânticas dos sintagmas nominais de uma sentença com o verbo e pode se expressar através de mecanismos lingüísticos. Para Givón (1984), os diferentes sistemas de marcação constituem soluções tipológicas ao mesmo nexo funcional entre o papel semântico e a função pragmática dos argumentos de uma oração. Uma variedade de fenômenos lingüísticos pode estar associada com a marcação de caso e, portanto, estreitamente ligados às relações gramaticais, semânticas ou pragmáticas.

De acordo com Dixon (1994, p. 6), todas as línguas distinguem a sentença intransitiva das transitivas. A primeira envolve um verbo e um sintagma nominal, enquanto a segunda envolve um verbo e dois ou mais sintagmas nominais. Cada língua, portanto, funciona em termos de três primitivas relações sintáticosemânticas: A, S, P (COMRIE, 1978) ou A, S, O, de acordo com Dixon (op. cit.) $\mathrm{S}$ corresponde ao argumento monovalente de um verbo intransitivo, enquanto A e O referem-se, nas cláusulas transitivas, ao argumento agenciador da ação e $\mathrm{O}$, ao argumento afetado ou paciente.

Existem dois sistemas básicos de marcação de caso: o nominativo-acusativo e o ergativo-absolutivo. Um sistema de marcação de caso do tipo nominativo-acusativo trata A e S da mesma forma e $\mathrm{O}$ de forma distinta. Um sistema ergativo-absolutivo identifica S e O com a mesma marca morfológica, ao passo que A é marcado diferentemente. A partir dessas relações, podemos dizer que as línguas nominativo/acusativas expressam A e $\mathrm{S}$ no caso nominativo, enquanto que as línguas ergativo-absolutivas expressam A no caso ergativo. Geralmente, a função S não ć morfologicamente marcada, tendo em vista que, ocorrendo como único argumento externo de um verbo intransitivo, nāo concorre com outros constituintes. Em um sistema ergativo-absolutivo, entretanto, em 
que existe a necessidade de estabelecer distinções entre os argumentos verbais, torna-se necessária a marcação morfológica de A, ao mesmo tempo em que $\mathrm{O}$ é o termo não-marcado.

O sistema ergativo-absolutivo, nos estudos tipológicos, é visto como complementar ao sistema nominativo-acusativo (DIXON, 1994, p. 1). Isso se deve ao fato de que, com o passar do tempo, esses sistemas vão alterando gradativamente a marcação de caso, o que faz com que $S$ e A recebam o mesmo tratamento, sendo marcados pelo caso nominativo, ao passo que $O$, em oposição a $S$ e A, é marcado como acusativo. Os dois sistemas aparecem em muitas línguas, resultando em vários tipos de cisões condicionadas pela natureza semântica de um ou de vários componentes obrigatórios da oração: nomes, verbos, TAM (Tempo, Aspecto e Modo) ou ainda pela distinção entre orações principais e coordenadas (DIXON, 1994, p. 2).

A língua Yawanawá possui um sistema de marcação de caso do tipo ergativo-absolutivo. A marcação de caso ergativo caracterizase pela nasalização da última vogal do SN que desempenha a função de A, ocasionando uma sílaba travada do tipo VC, ou por um morfema monossilábico morfema $\{-n \notin n /$-haun $\}$, que tem sua realização condicionada pelas características do $\mathrm{SN}$ a que se agregará. O caso absolutivo, sem nenhuma marca morfológica foneticamente realizada, é representado por $\mathrm{O}$, o que pode ser observado nos exemplos de 01 a 04.

$$
\begin{array}{lll}
\text { ißastißu-n } & \text { visku- } & \int z t z-a \\
\text { NP-Erg } & \text { NP-Abs beijar-Pas' } \\
\text { 'Ivaistivu beijou Visku' } &
\end{array}
$$

As abreviaturas usadas neste trabalho sāo: Abs - Absolutivo, AnF - Ação nāoFinalizada, AF - Ação Finalizada, Des - Desiderativo, Erg - Ergativo, Foc - Foco, Hum - Humano, NP - Nome Próprio, Pas - Passado imediato, Pas 1 - Passado próximo, Pl - Plural. 
(02) $¥-\mathrm{n}$ iuma-ø pi-pai

1s-Erg peixe-Abs comer-Des

'eu quero comer peixe'

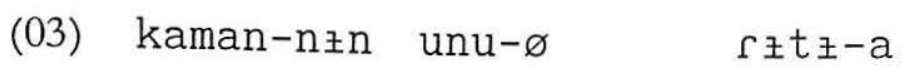

cachorro-Erg porquinho-Abs matar-Pas

'o cachorro matou o porquinho'

(04) a-hu-hu-haun mamanø aia-pai-kani

3s-Pl-Hum-Erg caiçuma-Abs beber-Des-AnF

'eles querem beber caiçuma'

\section{Cisäo no sistema de marcação de caso}

A língua Yawanawá se utiliza de elementos morfofonológicos como estratégia para a marcação do caso ergativo. A atribuição dos papéis semânticos dos argumentos verbais está diretamente relacionada aos tipos semânticos dos verbos, que podem ser classificados em transitivos e em intransitivos ativos e estativos. $\mathrm{O}$ padrão ergativo se manifesta, portanto, pela natureza da relação entre os verbos e seus argumentos.

Segundo as convenções propostas por Dixon $(1979,1994)$ e tomando por base a natureza semântica do verbo, a língua Yawanawá codifica A como sujeito de verbos transitivos; O como objeto direto de orações transitivas e em relação aos verbos intransitivos: $S_{a}$ para sujeitos de verbos intransitivos ativos e $\mathrm{S}_{0}$ para sujeitos de verbos intransitivos estativos. Desta forma, A se parece semanticamente com $S_{a}$, no sentido de que ambos exercem controle sobre a atividade realizada. $S_{0}$ se parece com $O$, tendo em vista que são afetados pela atividade realizada. 
As considerações acima podem ser aplicadas ao sistema (pro)nominal da língua Yawanáwa, tendo em vista que a marcação de caso está de acordo com o significado prototípico do verbo e os argumentos verbais, por conseqüência, são marcados com base em sua função semântica. Essas regras, entretanto, não se aplicam ao SN que desempenha função de sujeito de um verbo intransitivo ativo quando representado pela terceira pessoa, tanto no sistema nominal quanto no pronominal. Nesse caso, a marcação é idêntica à do SN que funciona como sujeito de verbo intransitivo estativo, ou seja, $\mathrm{S}_{\mathrm{o}}$, como nos exemplos:

(05) aua-ø uaka mıгa pakı-a anta-Abs água dentro cair-Pas 'a anta caiu no rio'

(06) iskuhu-ø-hu nui-a japó-Abs-Pl voar-Pas 'os japós voaram'
(07) a-ø-hu-hu munu-tiru-hu
3s-Abs-Hum-Pl dançar-AF-Pl
'eles dançaram'

A cisão no sistema de marcação de caso da língua condicionado pela natureza semântica do verbo vai atingir apenas as formas de terceira pessoa, ocasionado um sistema de sujeito cindido ('split-S'), nos termos de Dixon (1994). O sub-sistema de sujeito cindido realiza-se através de regras sintáticas relacionadas a um esquema prototípico. A marcação de $\mathrm{S}_{\mathrm{a}}$ e $\mathrm{S}_{\mathrm{o}}$ baseia-se no significado 
prototípico do verbo: $S_{a}$, quando o referente de $\mathrm{S}$ controla a ação; e, $\mathrm{S}_{\mathrm{o}}$ caso não exista nenhum controle (DIXON, 1994, p. 78-9). No sistema ergativo, portanto, existe a oposição entre $\mathrm{S} / \mathrm{O}$ e $\mathrm{A}$; no sistema nominativo, S/A opõem-se a $\mathrm{O}$; e, no subsistema sujeito cindido, temos a oposição entre $\mathrm{S}_{\mathrm{a}} / \mathrm{A}$ e $\mathrm{S}_{\mathrm{o}} / \mathrm{O}$.

A língua Yawanawá, portanto, possui um sistema de sujeito cindido, resultante da divisão entre $S_{a}$ e $S_{o}$, quando o $S N$ que ocupa a função de sujeito é preenchido por um (pro)nome correspondente à terceira pessoa, o que significa dizer que o mesmo não participa do eixo falante-ouvinte, sendo apenas um referente externo ao processo comunicativo.

(08)

\begin{tabular}{|l|l|l|l|}
\hline & A/As & O/So & V \\
\hline a) & $\begin{array}{l}\text { nu-n-hin } \\
\text { 1p-Erg-Foc }\end{array}$ & & $\begin{array}{l}\text { Susu-tiru } \\
\text { Brincar-AF }\end{array}$ \\
\hline b) & $\begin{array}{l}\text { nukzßznz-n } \\
\text { homem-Erg }\end{array}$ & $\begin{array}{l}\text { kari-ø } \\
\text { batata-Abs }\end{array}$ & $\begin{array}{l}\text { Bana-Sinna } \\
\text { Plantar-Pas 1 }\end{array}$ \\
\hline c) & & $\begin{array}{l}\text { aa-ø-hin } \\
\text { ss-Abs-Foc }\end{array}$ & $\begin{array}{l}\text { SuSu-tiru } \\
\text { Brincar-AF }\end{array}$ \\
\hline
\end{tabular}

a) 'nós brincamos'

b) 'o homem plantou batata'

c) 'ele brincou'

Pelos exemplos de (08), podemos ver que A e Sa recebem a marca de ergatividade, através do morfema $\{-n\}$; enquanto $O$ e $S_{\text {o }}$ se comportam de maneira semelhante ao serem marcados 
absolutivamente através de $\varnothing$. Tais realizações podem ser justificadas tomando por base uma hierarquia de agentividade, em que o falante impõe sua visão de mundo e se comporta como principal agenciador dos eventos, o ouvinte vem logo em seguida; e, por último, uma terceira pessoa, não diretamente envolvida no processo comunicativo. Dessa forma, baseados em Dixon (1994, p. 85), podemos escalonar a primeira e a segunda pessoas como detentoras de maior agentividade, situando-as como elementos mais à esquerda da escala, enquanto a terceira pessoa e os nomes, com maior probabilidade de funcionarem como pacientes, situam-se mais à direita.

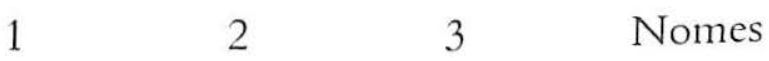

Figura 01 - Hierarquia nominal

De forma diferente de outras línguas Pano (Cf. VALENZUELA, 2000 e FERREIRA, 2001), a língua Yawanawá parece exibir um sistema em que a primeira e segunda pessoas apresentam maior potencial agentivo que a terceira pessoa e os nomes. Salvo engano, a distinção, adotada por Dixon (1994), entre nomes próprios e comuns e entre animados e inanimados, parece irrelevante para a análise da língua em questão.

\section{Conclusão}

A língua Yawanawá se utiliza de elementos morfofonológicos como estratégia para atribuição de caso, que está de acordo com o significado prototípico do verbo e os argumentos verbais, por consequiência, são marcados com base em sua função semântica. Estas regras, entretanto, não se aplicam ao SN que desempenha função de sujeito de um verbo intransitivo ativo quando representado 
pela terceira pessoa, tanto no sistema nominal quanto no pronominal. Neste caso, a marcação é idêntica à do SN que funciona como sujeito de verbo intransitivo estativo, ou seja, $S_{o}$, ocasionando uma cisão no sistema de marcação de caso da língua condicionado pela natureza semântica do verbo. Se considerarmos que uma cisão no sistema de marcação de caso aponta para uma mudança em curso, podemos dizer que na língua Yawanawá o processo de mudança começou pela terceira pessoa.

\section{Referências}

CHUNG, Sandra \& TIMBERLAKE, Alan. Tense, aspect and mood. In. SHOPEN, Timothy (Ed.). Language typology and syntactic description. Vol. III. Cambridge: Cambridge University Press, 1995. p. 202 - 258.

COMRIE, B. Ergativity. In: Lermann P. Winfred (Ed.). Syntatic typology: studies in the phenomenology of language. Austin/Londres: University of Texas Press, 1978. p. $329-394$.

DE PAUla, Aldir Santos de. A língua dos índios da aldeia Barão: aspectos fonológicos e morfológicos. Dissertação (Mestrado). Universidade Federal de Recife, Recife, 1992.

. A língua dos índios yawanawá do Acre. Tese (Doutorado) - Instituto de Estudos da Linguagem, Universidade Estadual de Campinas, Campinas, 2004.

COSTA, Raquel G. R. Manisfestaciones de la ergatividad em Marubo (Pano). Actas de las II Jornadas de Linguistica Aborigen. Buenos Aires, 1994. p. 205-23.

Aspects of ergativity in Marubo. Iournal of Amazonian Language 1 (2), p. 50-103, 1997. 
- Aspectos da fonologia Marubo (Pano): uma visão não-linear. Tese (Doutorado), Universidade Federal do Rio de Janeiro, Rio de Janeiro, 2000.

DIXON, R.M.W. Ergativity. Cambridge: Cambridge University Press, 1994.

FERREIRA, Rogério Vicente. Língua Matís: aspectos descritivos da morfossintaxe. Dissertação (Mestrado) - Instituto de Estudos da Linguagem, Universidade Estadual de Campinas, Campinas, 2001.

GIVÓN, T. Syntax: a functional-typological introduction. Vol. I. Amsterdam/Philadelphia: John Benjamins, 1984.

Syntax: a functional-typological introduction. Vol. II. Amsterdam/ Philadelphia: John Benjamins, 1990.

HOPPER, Paul J. \& THOMPSON, Sandra A. Transitivity in grammar and discourse. Language 56(2), p. 251-99, 1980.

VALENZUELA, Pilar. Ergatividad escindida en Wariapano, Yaminawa y shipibo-konibo. In: VAN DER VOORT, Hein \& VAN DE KERKE, Simon. Ensaios sobre lenguas de las tierras bajas de Sudamèrica: contribuciones al $49^{\circ}$ Congresso Internacional de Americanistas em Quito, 2000. 